effects. As a working hypothesis the long-term aggravation of the alcohol withdrawal response in the CNS is a non-mitogenic expression of oncogene activity in the neurons elicited by recurrent intoxication and/or withdrawal episodes. At the biochemical level, such a hypothesis may again receive support from reports indicating that oncogenes in normal neurons modulate several basic physiological processes essential to neuroexcitability and including receptors, neuropeptides, neurotransmitters, cellular second-messenger systems and calcium metabolism (Leach, 1991).

According to this hypothesis, the fully developed alcohol withdrawal syndrome is not an expression of physical dependence per se, but the result of an aberrant encoding of neuronal 'memory for excitability' extended gradually throughout large populations of neurons. Such an extended 'neuronal conversion' to a deviant potential for excitation/synaptic efficacy may come about by the activation of some of the basic mechanisms that determine differentiation and extension of neuroexcitatory characteristics in functional systems of the brain.

This theory is open to investigation both in man and in experimental animals when coupling regional measurements of oncogene activity with cognitive/ behavioural testing.

Ballenger, J. \& Post, R. M. (1978) Kindling as a model for alcoholic withdrawal syndrome. British Journal of Psychiatry, 133, $1-14$.

Kalant, H., Leblanc, A. E. \& Gibbins, R. J. (1971) Tolerance to and dependence on, some non-opiate psychotropic drugs. Pharmacology Review, 23, 135-191.

LEACH, J. (1991) The functional psychoses - are oncogenes involved in their pathogenesis? Some speculations. British Journal of Psychiatry, 158, 563-568.

LıPowski, Z. L. (1990) Delirium: Acute Confusional States. New York: Oxford University Press.

MAJCHROWICZ, E. (1975) Induction of physical dependence upon ethanol and the associated behavioral changes in the rat. Psychopharmacology. 43, 245-254.

Department of Psychiatry E

R. HEMMINGSEN B. GLENTHØJ

Bispebjerg Hospital

Bispebjerg Bakke 23

DK-2400 Copenhagen NV

Denmark

\section{Politically motivated suicides}

SIR: Among various types of suicide described by Durkheim (1952) anomic is the one closly related to the political state of the country. In India, dowry- related self-immolations have been well known (Rao et al, 1989). In their sample of 100 female burns cases, they reported that the age group of their subjects was 15-40 and the common causes of suicide by burns included marital problems and interpersonal difficulties with other family members. Contrary to other reports, only $16 \%$ of their sample showed evidence of psychiatric disorders. The ratio of attempters to completers by this method was $1: 23$ - a reversal of the one noticed in other reports. Burns have largely been reported from younger females.

On a recent visit to India, I was able to observe the media reports of suicide. Following the declaration by the then Prime Minister to reserve an increased proportion of jobs for the lower castes, the students, frightened of not being able to get jobs, took to the streets. On 19 September 1990, a 20-year-old male student set himself on fire in the presence of mass media. Tempers were running high because even after a nine-day hunger strike (another very Indian political tool) the students believed their cause had not received adequate attention. In frustration, the students came up with the idea of self-immolation. The night before, this student called home to say "we are staging a drama" (Kalra, 1990). This incident made the front page of every newspaper and set off a chain reaction of unprecedented self-immolation attempts. In addition, students took overdoses, cut their throats and ingested pesticide.

During one week, 55 suicides and 23 suicide attempts were reported. Of these, 46 were males. The commonest method was self-immolation, in 31 cases, followed by overdoses in 29 , and hanging in four cases. The age range was from 12 to 28 . However, one 68-year-old man killed himself in sympathy with the youngsters. At least one 14-year-old female alleged that she had been set on fire, but the police later withdrew this claim.

Suicide by self-immolation is often one way of political protest. This method of suicide has been reported from India. However, this was the first epidemic of suicide which involved men and public selfimmolation. The suicide notes that were reported in the press often blamed the Prime Minister and the authorities. This rash of suicides does not represent any psychiatric pattern but more of a socio-political one. It could be argued that the series is a consequence of the state of anomie in the country reflecting a political decision taken by the Prime Minister without consultation with a broader population. A private act of suicide was thus turned into a public one. At least one student reportedly asked whether she had appeared on the TV or not. In spite of the psychiatrists' appeal to the media to dampen their coverage in order to dissuade others from killing 
themselves there was no let up until early November when other major political events took over the front pages. The first attempter's initial plans for a mock self-immolation had gone awry (Kalra, 1990). It would appear that this attempt was an outlet for suppressed frustration and anger where the perpetrator chose the easiest and the most dramatic course of action to resolve his problems of identity by making a bid for glorious freedom (Kumar, 1990). Some of the subsequent suicides may have been purely for personal reasons but the media coverage and the political context may have offered them a way out by sanctification.

Durkheim, E. (1952) Suicide (transl. Simpson). London: Routledge \& Kegan Paul.

KALRA, M. (1990) Act of desperation. India Today, 15 October, 27.

KumAR, R. S. (1990) Like wild fire. Times of India Sunday Review', 21 October, 2.

RaO, A. V., Mahendran, N., Gopalakrishnan, C. et al (1989) One hundred female burns cases: a study in sociology. Indian Journal of Psychiatry, 31, 43-50.

Institute of Psychiatry

DiNeSh BHUGRA

London SE5 8AF

\section{NMS and genetic drug oxidation}

SIR: Our recent paper (Otani et al, Journal, June $1991,158,850-853$ ) of the familial occurrence of NMS suggests that the predisposition to this syndrome may be related to a genetic factor. Meanwhile, the genetically determined oxidation polymorphism is involved in the metabolism of haloperidol (Gram et al, 1989) and perphenazine (Dahl-Puustinen et al, 1989) is related to the debrisoquine/sparteine/ metoprolol-type polymorphism, whereas that of diazepam is dependent on the mephenytoin polymorphism (Bertilsson et al, 1989). Therefore, we studied whether patients developing NMS would show an impaired drug oxidation capacity (i.e. poor metaboliser status).

The subjects were five patients with NMS. Patient 1 was the mother, and patient 2 was the elder daughter described in our recent report. Patient 3 (68-year-old female), patient 4 (20-year-old female), and patient 5 (63-year-old male) were unrelated by lineage and birth. Patients 1, 3 and 4 developed two episodes. At the onset of the first episode of patient 3, serum haloperidol level was $16 \mathrm{ng} / \mathrm{ml}$ (daily dose $10 \mathrm{mg}$ ), and at the second episode of patient 4 , serum zotepine level was $9 \mathrm{ng} / \mathrm{ml}$ (daily dose $40 \mathrm{mg}$ ). The assessment of oxidation capacity (i.e., phenotyping test) by metoprolol tartrate $(100 \mathrm{mg})$ and racemic mephenytoin $(100 \mathrm{mg})$, which are metabolised by two independently different P-450 isozymes (Horai et al, 1989), was conducted after recovery from NMS, with their consent. At the time of the phenotyping test, all but patient 2 were taking one or two benzodiazepines such as alprazolam, diazepam, flunitrazepam, and nitrazepam, and patient 1 was also taking zotepine. The phenotyping procedure was similar to that in our previous study (Horai et al, 1989), except that the two test drugs were administered simultaneously. Oxidation capacities of metoprolol and mephenytoin were expressed by the $\log _{10}$ urinary metoprolol/a-hydroxymetoprolol ratio $\left(\log _{10}\right.$ metabolic ratio (MR)) and the $\log _{10}$ percentage of urinary excretion of 4-hydroxymephenytoin per the dose administered as racemate mephenytoin $\left(\log _{10} 4-\mathrm{HM} \%\right.$ of dose), respectively. Their phenotyping test values $\left(\log _{10} \mathrm{MR}\right.$ and $\log _{10} 4-\mathrm{HM} \%$ of dose) were as follows: -0.240 and 1.26 in patient 1 , -0.323 and 1.21 in patient $2,-0.210$ and 1.04 in patient $3,-0.991$ and 1.20 in patient 4 , and 0.238 and 1.41 in patient 5 .

Contrary to our hypothetical expectation, all the cases showed a normal oxidation capacity (extensive metaboliser status) of both the test drugs according to the phenotyping criteria used in our previous Japanese population study (Horai et al, 1989). One may wonder if the phenotypic expression in four of the five cases might have been modified by the possible drug interactions, because they were taking a neuroleptic and/or benzodiazepines when phenotyped. However, if this were the case, the oxidation status should have changed from an extensive to poor metaboliser phenotype. Serum levels of neuroleptics measured at the onset of NMS were not toxic in the two patients; the haloperidol level in patient 3 was within the therapeutic window proposed by Santos et al (1989). The zotepine level in patient 4 was within the range similar to the previously reported 21 patients (i.e. $5-317 \mathrm{ng} / \mathrm{ml}$ ) without developing any significant side effects including NMS. Therefore, this report suggests that the development of NMS appears to be ascribable neither to a genetically determined impaired drug oxidation nor to a toxic neuroleptic level.

Bertilsson, L., Henthorn, T. K., SANZ, E., et al (1989) Importance of genetic factors in the regulation of diazepam metabolism: relationship to S-mephenytoin, but not debrisoquin, hydroxylation phenotype. Clinical Pharmacology \& Therapeutics, 45. 348-355.

Dahl-Puustinen, M-L., Lidén, A., Alm, C., et al (1989) Disposition of perphenazine is related to polymorphic debrisoquin hydroxylation in human being. Clinical Pharmacology \& Therapeutics, 46, 78-81. 